\title{
Pyrolysis of coconut shell to produce crude oil
}

\author{
Rahul G. Bhad ${ }^{* 1}$, Sejal R. Sedani ${ }^{1}$ and Snehal N. Dongerdive ${ }^{2}$ \\ ${ }^{1}$ College of Agricultural Engineering and Technology, Jalgaon Jamod, Maharashtra. \\ ${ }^{2}$ Department of Electrical and Other Energy Sources, College of Agricultural Engineering and \\ Technology, Jalgaom Jamod, Maharashtra. \\ *Email: rahul.bhad5@gmail.com
}

\begin{abstract}
Slow pyrolysis experiment of coconut shell had been conducted to determine the effect of pyrolysis temperature, heating rate and particle size on the pyrolysis product yield. Pyrolysis experiment were performed at pyrolysis temperature above $800^{\circ} \mathrm{C}$ with a heating rate of $60^{\circ} \mathrm{C} / \mathrm{min}$ for $7 \mathrm{~min}, 8 \mathrm{~min}, 9$ min and particle size of $5-50 \mathrm{~mm}$. The highest liquid yield was obtained at a pyrolysis temperature $820^{\circ} \mathrm{C}$, particle size $5-7 \mathrm{~mm}$, with a heating rate of $60^{\circ} \mathrm{C} / \mathrm{min}$ for $9 \mathrm{~min}$. The field of obtain char, liquid and gas was $34 \%, 56 \%$, and $10 \%$ respectively at different pyrolysis conditions. The result indicates that the effect of pyrolysis temperature and particle size on the pyrolysis yield is more significant than that of heating rate and residence time.
\end{abstract}

Keywords: Crude oil, Coconut Shell, Pyrolysis, Renewable energy.

Paper cited: Bhad, R.G., Sedani, S.R. and Dongerdive, S.N. (2020). Pyrolysis of coconut shell to produce crude oil. South Asian Journal of Food Technology and Environment, 6(1): 917-922.

\section{Introduction}

The diesel engines dominate the field of commercial transportation and agricultural machinery due to its ease of operation and higher fuel efficiency. The consumption of diesel is 4-5 times higher than petrol in India. Due to the shortage of petroleum products and its increasing cost, efforts are on to develop alternative fuels especially, to the diesel oil for full or partial replacement (Puhan et al., 2017). Coconut shell is an agricultural waste and is available in plentiful quantities throughout tropical countries worldwide. In many countries, coconut shell is subjected to open burning which contributes significantly to $\mathrm{CO}_{2}$ and methane emissions. The traditional pit method of production has a charcoal yield of 25-30\% of the dry weight of shells used (Yerima and Grema, 2018). The smoke evolved from pit method is not only a nuisance but also a health hazard.
Coconut production plays an important role in India. India accounts for 28.54 per cent of the world's coconut production and is one of the major players in the world's coconut trade. Coconut husks have a high amount of lignin and cellulose and that is why it has a high calorific value of 3500$4000 \mathrm{kcal} / \mathrm{kg}$, Ash content $4 \%-5 \%$ and a moisture content of $15 \%$ (Yong et al., 2009). The chemical composition of coconut water consists of sugar, vitamins, minerals; amino acid and phytohormones (Yong et al., 2009), husks consist of, water-soluble $5.25 \%$, pectin and related compounds $3.00 \%$, hemicellulose $0.25 \%$, lignin, $45.84 \%$, cellulose $43.44 \%$ an ash $2.22 \%$ (Young et al., 2009). The predominant use of coconut husks is in direct combustion in order to make charcoal; otherwise, husks are simply thrown away and can be injurious but can be transformed into a value-added fuel source which can replace fuel wood and other traditional fuel sources. In terms of availability and costs of coconut 
husks, they have good potential for use in a power plant. The leftover fiber from coconut oil, coconut milk production and coconut meal is used as livestock feed. The dried calyx is used as fuel in a wood-fired stoves Coconut water is traditionally used as a growth supplement in plant tissue culture/micropropagation (Yong et al., 2009). Coconut shell is more suitable for pyrolysis process as it contain lower ash content, high volatile matter content and available at a cheap cost. The coconut shells generated from oil industry and various uses of coconut need to be utilized properly. Incineration leads to various environment related problems. These coconut shells will be better utilized if they are pyrolyzed.

Pyrolysis is the thermochemical decomposition of organic matter in the absence of oxygen and produces a wide range of useful products. During pyrolysis, complex macromolecules of biomass break down into relatively smaller molecules producing, three major products that can be classified as follows:

a. A solid residue (consisting mainly of carbon and ash) known as char

b. Gases (mainly $\mathrm{CO}, \mathrm{CO}_{2}, \mathrm{CH}_{4}, \mathrm{H}_{2}$ and other light hydrocarbons) and

c. Vapours/liquids known as bio-oil or biocrude (mainly oxygenates, aromatics, water, products of low degree of polymerization, tars, etc.)

Depending on the operating condition, pyrolysis can be classified into three main categories: Conventional/Slow, fast and flash pyrolysis. These differ in process temperature, heating rate, solid residence time, biomass particle size, etc. However, relative distribution of products is dependent on pyrolysis type and pyrolysis operating parameters.

\section{Materials and Method}

\section{Collection Raw materials}

Coconut shells had been collected from nearest temples of Jalgaon (Jamod) and size was reduced before pyrolysis. Coconut shell, water as cooling medium, match box, electric tape, wooden blocks are used for experiments.

\section{Preparation of Raw Material}

Coconut Shell size reduction: Size of coconut shell was reduced by using hammer. The size of coconut shell taken for experiment was in the range it $5-50 \mathrm{~mm}$. experiment was carried out in different groups with different size of coconut shell.

Removal of moisture: Before putting coconut shells for co-pyrolysis, they were processed to be reduced to fine particles. Coconut shells were dried in sun, and then hand crushed to particle size less than $5-50 \mathrm{~mm}$, the pieces which were then dried in oven at $105^{\circ} \mathrm{C}$ for removal of moisture.

Components and elemental analysis of Coconut shell: The Proximate and Ultimate Analysis of coconut shell was carried out and the results are shown in Table (1) and Table (2) respectively. The different components of coconut shell is shown in Table (3).

\section{Experimental procedure}

Clean the apparatus and arrange it as shown in Fig. 2. Weight the small pieces of coconut shell and put it in conical flask. Place the conical flask on tripod stand and arrange the assembly as shown in figure. Fill the water reservoir with water. Start heating of coconut shell. Measure the temperature of flame. The coconut shell was burned in absence of air in conical flask fitted with rubber cork. As the brown colour vapours of bio oil start evolving the shell. They are allowed to pass through the connecting pipe whose one end was attached to the water cooled condenser and other end to conical flask. The vapours get condensed in condenser and bio oil was collected in the beaker placed below other end of condenser. The condenser was placed in vertical direction. Along with the vapours we got non condensable gas which was flammable in nature. Heating was continued upto 10 mins. Experiment was carried out in different 4 groups with different size of coconut shell and different heating time. Collect the bio oil and 
weight it. Also measure the quantity of biochar

retained in conical flask.

obtained after completion of the process

Table 1: Proximate analysis of coconut shell

\begin{tabular}{|c|c|c|c|c|}
\hline Moisture & Volatiles & Ash & Fix-C & S \\
\hline $10.7 \%$ & $68.2 \%$ & $0.6 \%$ & $21.6 \%$ & $0.02 \%$ \\
\hline
\end{tabular}

Table 2: Ultimate analysis of coconut shell

\begin{tabular}{|c|c|c|c|c|}
\hline $\mathbf{C}$ & $\mathbf{H}$ & $\mathbf{N}$ & $\mathbf{O}$ & $\mathbf{C l}$ \\
\hline $48.6 \%$ & $6.0 \%$ & $0.1 \%$ & $44.2 \%$ & $0.11 \%$ \\
\hline
\end{tabular}

Table 3: Different compounds of coconut shell

\begin{tabular}{|c|c|}
\hline Compound & Percentage \\
\hline Cellulose & 32.61 \\
Lignin & 38.51 \\
Pentosans & 25.27 \\
\hline
\end{tabular}

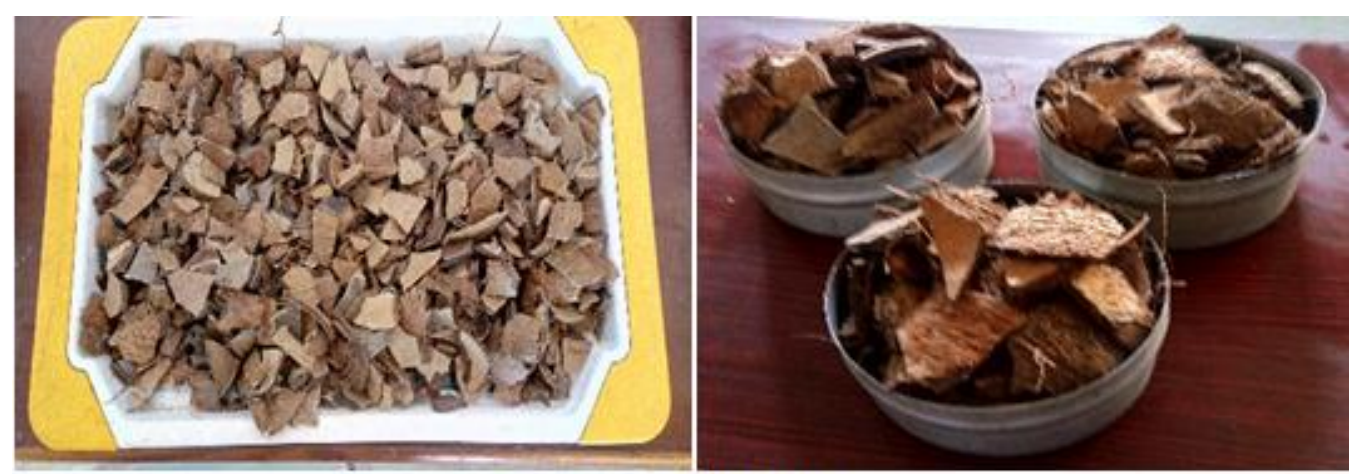

Fig. 1: Coconut Shell

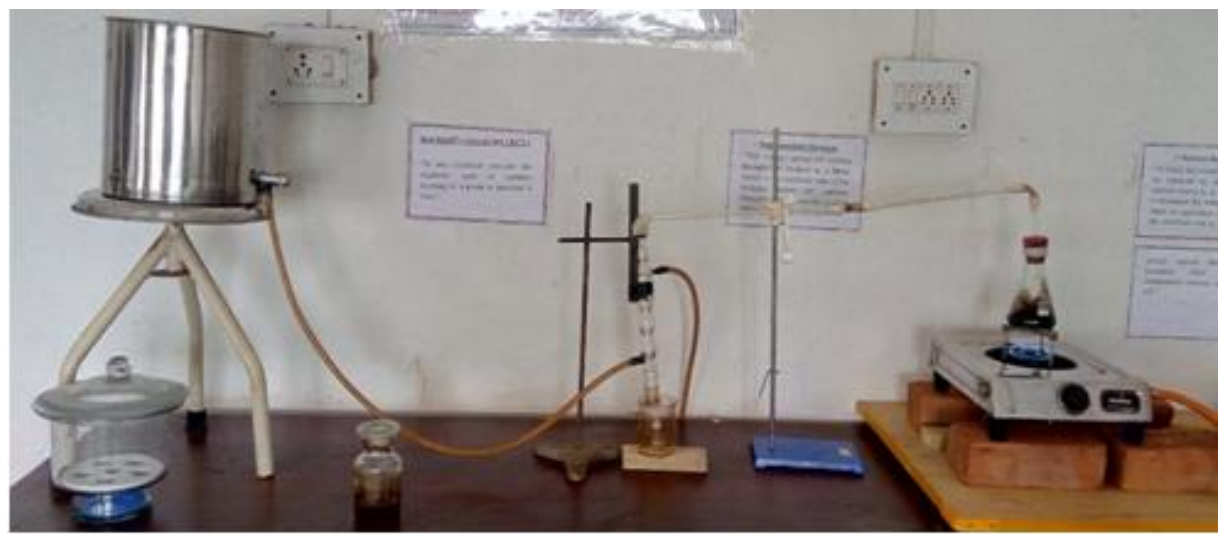

Fig. 2: Experimental Setup

\section{Results and discussion}

\section{Case 1(for 7 min)}

It was observed that the crude oil yield proportional with their weight little difference occurs due to some external losses like leakage etc. during the $7 \mathrm{~min}$ span the bio oil yield is in range of $40-48 \%$ by weight. The char obtained in the range of $25-30 \%$ by weight. The highest yield of crude oil obtained during observation when $200 \mathrm{~g}$ of coconut shell taken and burnt for $7 \mathrm{~min}$ in absence of air. The highest yield of char was obtained when the $250 \mathrm{~g}$ of sample was taken and burnt for 7 min in absence of air as shown in Fig. 3. 


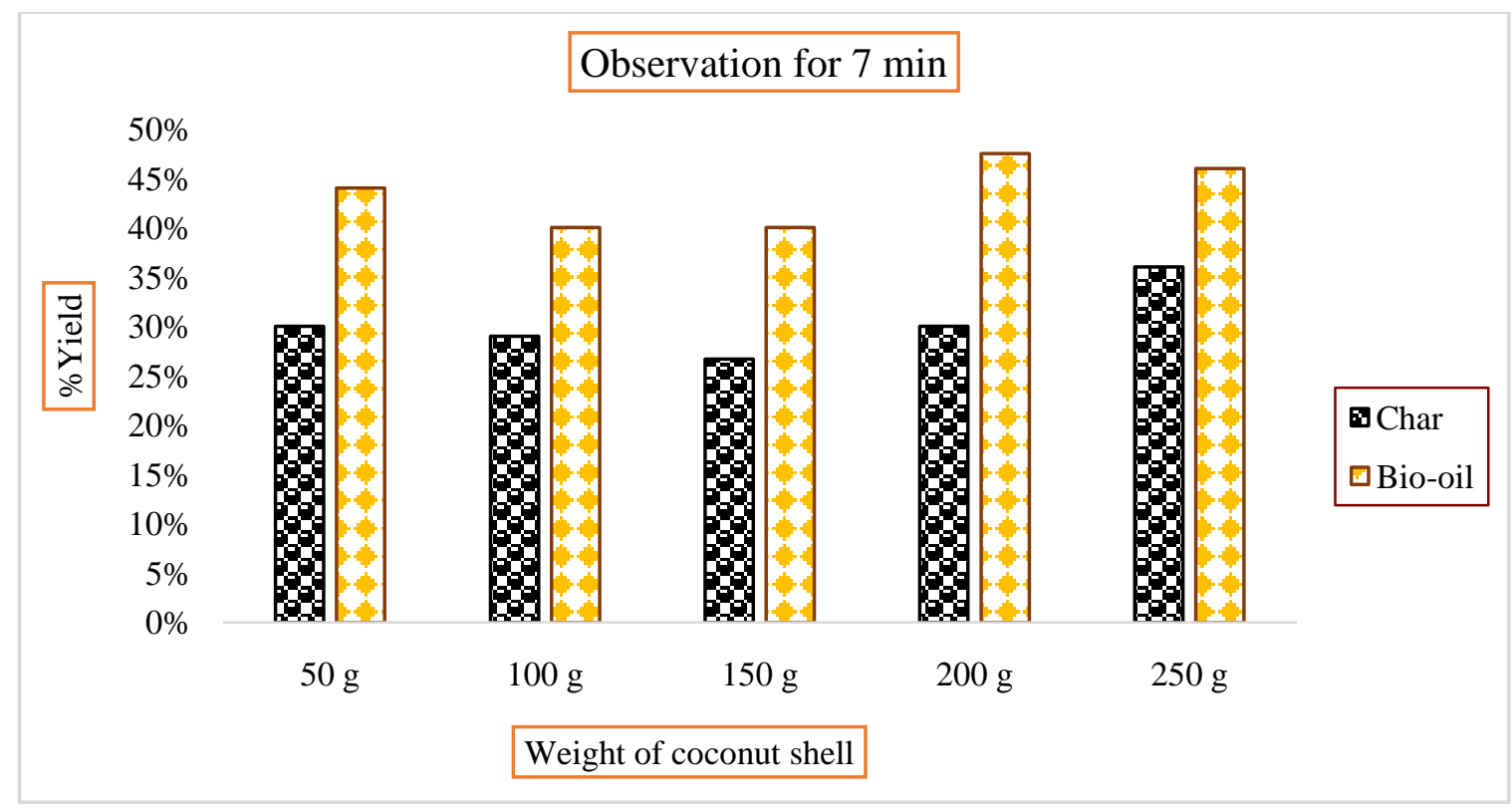

Fig. 3: Yield V/s Weight of Coconut Shell for $7 \mathrm{~min}$

Case 2 (for 8 min)

It was observed that the crude oil yield proportional with their weight little difference occurs due to some external losses like leakage etc. during the 8 min span the bio oil yield is in range of $45-49 \%$ by weight. The char obtained in the range of $20-36 \%$ by weight. The highest yield of crude oil obtained during observation when $200 \mathrm{~g}$ of coconut shell taken and burnt for $8 \mathrm{~min}$ in absence of air. The highest yield of char was obtained when the $250 \mathrm{~g}$ of sample was taken and burnt for 8 min in absence of air as shown in Fig 4.

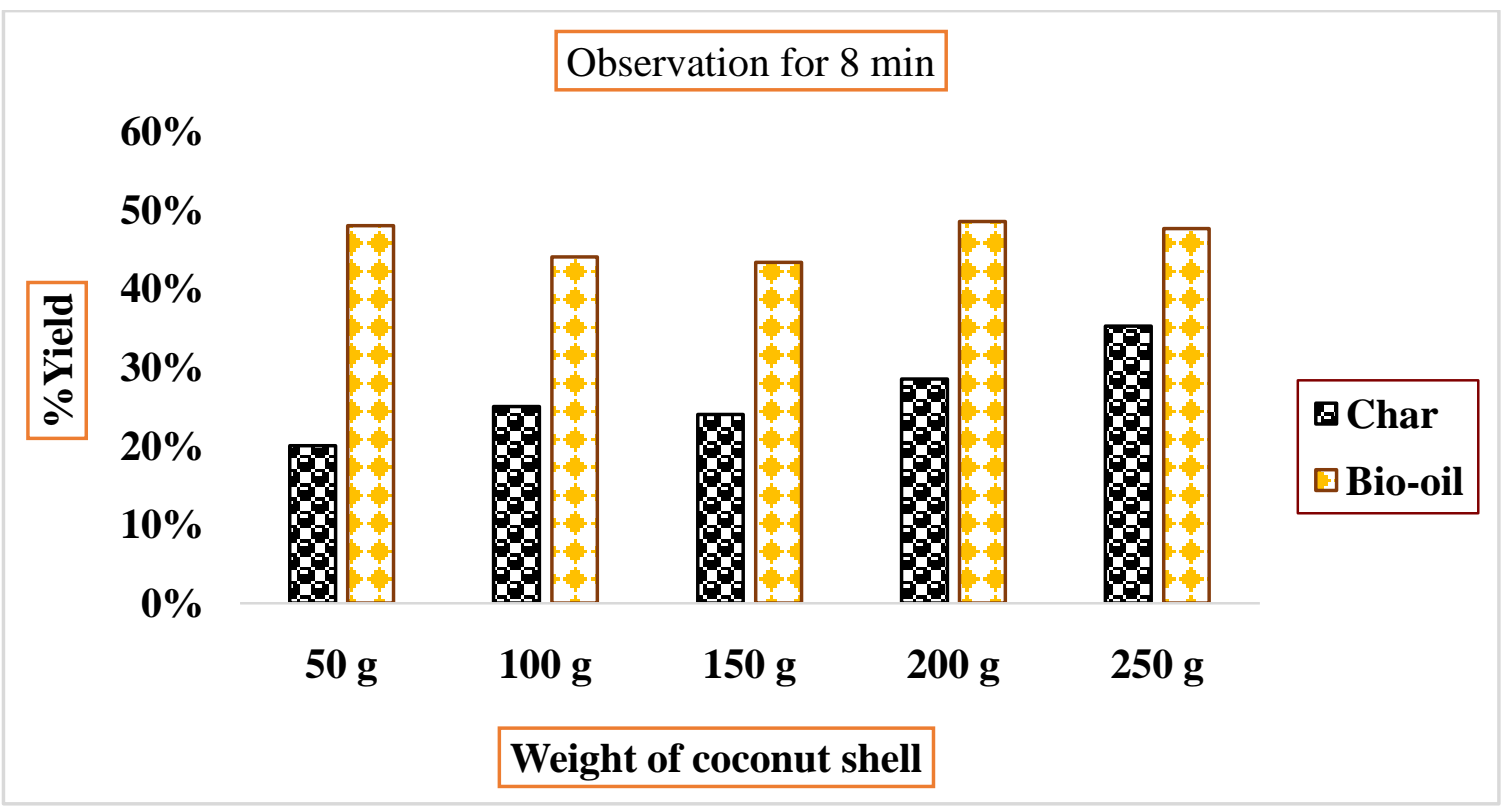

Fig. 4: Yield V/s Weight of Coconut Shell for $8 \mathrm{~min}$

Case 3 (for 9 mins)

It was observed that the crude oil yield proportional with their weight little difference occurs due to some external losses like leakage etc. during the $9 \mathrm{~min}$ span the bio oil yield is in range of $50-56 \%$ by weight. The char obtained in the range of $20-34 \%$ by weight. The highest yield of crude oil obtained during observation when $250 \mathrm{~g}$ of coconut shell taken and burnt for $9 \mathrm{~min}$ in absence of 
air. The highest yield of char was obtained

for 9 min in absence of air as shown in Fig 5 . when the $250 \mathrm{~g}$ of sample was taken and burnt

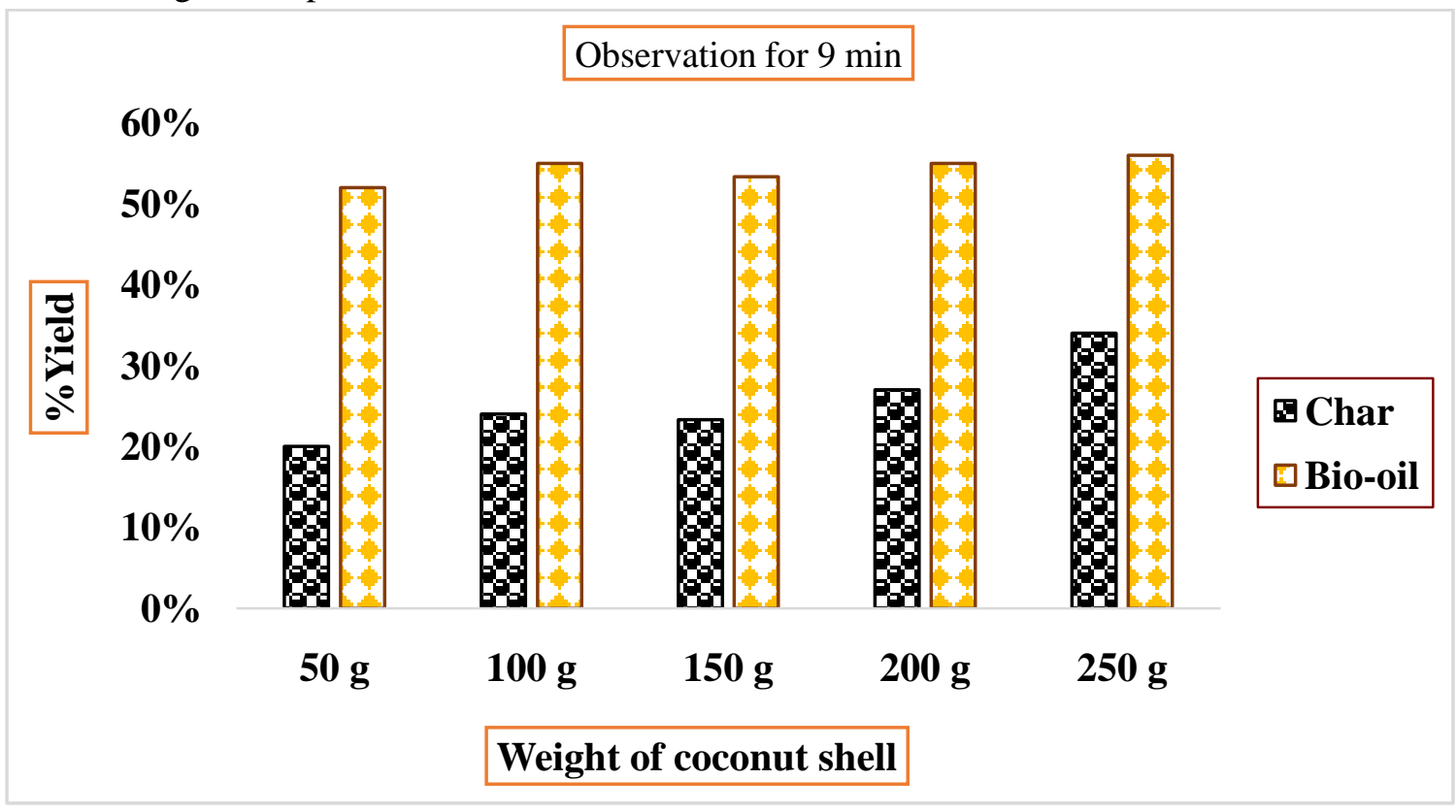

Fig. 5: Yield V/s Weight of Coconut Shell for 9 min

\section{Crude oil Production with respect to Time}

It has been observed that as the residence time increases the yield of bio oil increases (Fig. 6). Also the heating time increases the yield of crude oil. Following table gives the average value of final result based on above observations. It was observed that the crude oil yield proportional with their weight little difference occurs due to some external losses like leakage etc. during the 9 min span the bio oil yield is in range of 50$56 \%$ by weight. The char obtained in the range of $20-34 \%$ by weight. The highest yield of crude oil obtained during observation when $250 \mathrm{gm}$ of coconut shell taken and burnt for 9 min in absence of air. The highest yield of char was obtained when the $250 \mathrm{~g}$ of sample was taken and burnt for 9 min in absence of air.

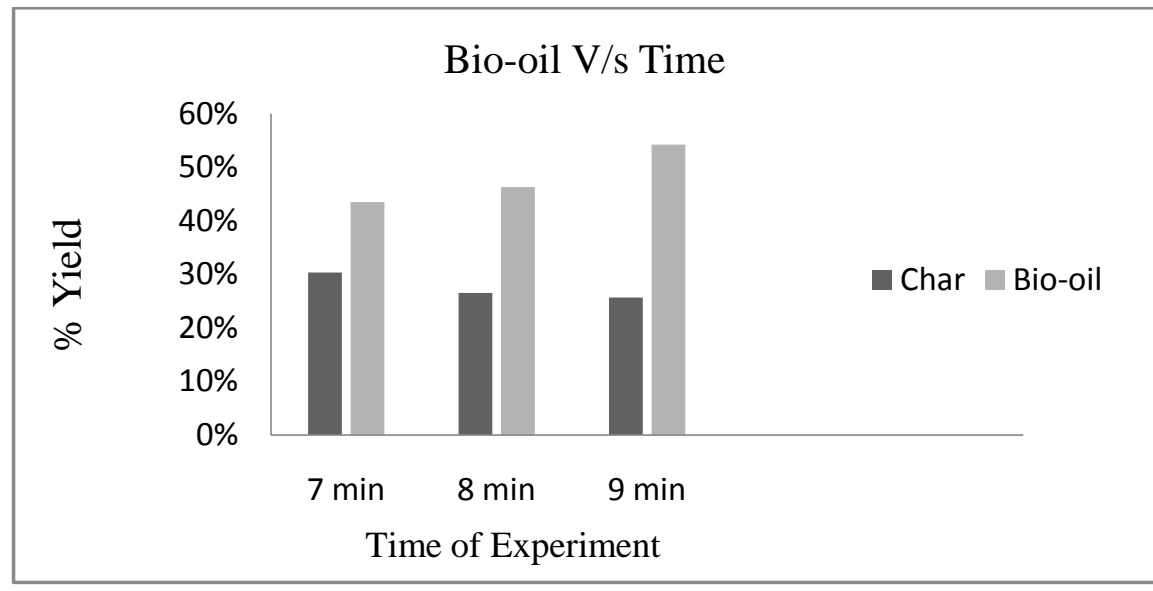

Fig 6: Crude oil Yield V/s Time 
Comparison of coconut shell pyrolysis oil with biomass derived pyrolysis oil and with diesel fuel

The Kinematic viscosity, density, flash point and HHV values of coconut shell was compared with date seed oil, tamarind seed oil and jute stick oil is shown in Table (4). The same said property was compared with diesel and heavy fuel oil is shown in Table (5).

\section{Table 4: Comparison of coconut shell pyrolysis oil with biomass derived pyrolysis oil}

\begin{tabular}{|l|c|c|c|c|}
\hline Analysis & Coconut shell & Date Seed oil & Tamarind seed oil & Jute stick oil \\
\hline Kinematic & 1.03 & 6.63 & 6.51 & 12.8 \\
viscosity $(\mathrm{cSt})$ & & & & \\
Density $\left(\mathrm{kg} / \mathrm{m}^{3}\right)$ & 1095.5 & 1042 & 1150 & 1224 \\
Flash Point $\left({ }^{\circ} \mathrm{C}\right)$ & 121 & 126 & 100 & $>70$ \\
HHV $(\mathrm{MJ} / \mathrm{kg})$ & 22.83 & 28.6 & 19.10 & 21.09 \\
\hline
\end{tabular}

Table 5: Comparison of coconut shell pyrolysis oil with diesel fuel

\begin{tabular}{|l|c|c|c|}
\hline Analysis & Coconut shell & Diesel & Heavy fuel oil \\
\hline Kinematic viscosity $(\mathrm{cSt})$ & 1.03 & 2.61 & 200 \\
Density $\left(\mathrm{kg} / \mathrm{m}^{3}\right)$ & 1095.5 & 827.1 & 980 \\
Flash Point $\left({ }^{0} \mathrm{C}\right)$ & 121 & 53 & $90-180$ \\
$\mathrm{HHV}(\mathrm{MJ} / \mathrm{kg})$ & 21.4 & 45.18 & $42-43$ \\
\hline
\end{tabular}

\section{Conclusion}

This research reveals that coconut shell has the basic values required of a good fuel, such as high caloric value, low moisture content, low ash, low $\mathrm{CO}_{2}$, no offensive odor and low velocity on combustion. During Pyrolysis, it was observed that sample size and time also imparts effect on production of crude oil. The highest yield of crude oil obtained during observation when $200 \mathrm{~g}$ of coconut shell taken and burnt for $7 \mathrm{~min}$ and $8 \mathrm{~min}$ in absence of air, while for 9 min sample size of $250 \mathrm{~g}$ yield maximum crude oil. Pyrolytic oil produced during pyrolysis of coconut shell has HHV of 21.4 MJ/kg and Flash point at $121^{\circ} \mathrm{C}$.

\section{References}

1. Puhan, S., Shau, B.B., Pradhan, R.R. and Chakravathy, K. (2017). The performance and emission characteristics of IC engines with different blends of diesel fuels. International Journal on Mechanical Engineering and Robotics, 4(1-2): 36-40.

2. Yerima, I. and Grema, M.Z. (2018). The Potential of Coconut Shell as Biofuel. The Journal of Middle East and North Africa Sciences, 4(8): 11-15

3. Yong, J.W., Ge, L., Ng, Y.F. and Tan, S.N. (2009). The chemical composition and biological properties of coconut (Cocos nucifera L.) water. Molecules, 14(12): 5144.

\begin{tabular}{|ll}
\hline Received & : February, 2020 \\
Revised & : March, 2020 \\
Published & : June, 2020
\end{tabular}

